\title{
CYTOTOXIC AND ANTIBACTERIAL ACTIVITIES OF MARINE SPONGE-DERIVED FUNGUS Aspergillus nomius NC06
}

\author{
Muh. Ade Artasasta ${ }^{1}$, Yanwirasti ${ }^{1}$, Muhammad Taher ${ }^{2}$, Akmal Djamaan $^{3}$ \\ and Dian Handayani, ${ }^{3 * *}$
}

${ }^{1}$ Departement of Biomedical, Faculty of Medicine, Andalas University, 25163 Padang, Indonesia

${ }^{2}$ Faculty of Pharmacy, International Islamic University Malaysia,

25200 Kuantan, Pahang, Malaysia

${ }^{3}$ Laboratory of Sumatran Biota, Faculty of Pharmacy, Andalas University,

25163 Padang, Indonesia

*E-mail: dianhandayani@ @ phar.unand.ac.id

\begin{abstract}
Sponge-derived fungi have attracted recent attention due to its important source of interesting biologically active compounds. In our previous study, we have obtained 13 fungi from marine sponge Neopetrsiachaliniformis. Among them, only Aspergillus nomius NC06 showed cytotoxic activity with the percentage of viability $113.9 \%$ and $70.31 \%$ of Vero cell and WiDr colon cancer cell, respectively. This study aimed to isolate the cytotoxic compound from the ethyl acetate extract of $N$. nomius NC06 using chromatography method. A total of 5 fractions of the extract obtained using vacuum liquid chromatography. These fractions were tested against HCT 116 colon cancer cell and ten human pathogenic bacteria. Fraction II, III, IV, and V showed cytotoxic activity with IC $_{50}$ of 5.28, 15.82, 10.27, and $45.57 \mu \mathrm{g} / \mathrm{mL}$, respectively. In antibacterial testing, fraction II and III were potential because of their ability to inhibit the growth of ten pathogenic bacteria with the diameter of inhibition zone more than $12 \mathrm{~mm}$.
\end{abstract}

Keywords: Sponge-derived fungi, Aspergillus nomius, Cytotoxicity, Antibacterial

(c) RASĀYAN. All rights reserved

\section{INTRODUCTION}

The sponge is known as the host for various microorganisms such as bacteria and fungi. ${ }^{1,2}$ But the association relationship and ecological function of microorganism in sponge body are remaining unclear ${ }^{3}$. However, microorganism associated with a sponge is known as natural resources to produce the potential bioactive compound. Especially marine sponge-derived fungi repeatedly show the potential bioactive compounds against various diseases such as cancer and pathogenic microbial infection. ${ }^{3-5}$

Thiel et al., (2007) figured out that the sponge-derived microorganisms mostly exist in cortex and endosome layers of sponge nevertheless the location of associated-fungi in the sponge is still unknown ${ }^{6}$. In addition, Kjeret al., (2010) published a protocol to isolate marine fungi from sponges and other marine macroorganisms. This protocol focused to isolate fungal to the marine sponge ${ }^{7}$. However, there are a lot of unknown interactions between sponges to its associated fungi. Furthermore, several studies have suggested that sponge-derived fungi have shown to exhibit interesting new bioactive sources that were previously unknown to originate from terrestrial starins ${ }^{8}$.

Aspergillus nomius was successfully isolated from marine sponge $N$. chaliniformis in our previous study. This fungus showed selectivity between cell normal Vero and WiDr colon cancer cell with the percentage of viability of $113,9 \%$ and $70,3 \%$, respectively. ${ }^{11}$ It is potential fungus to be continued to explore its bioactive compound.

\section{EXPERIMENTAL}

Sponge Material, Isolation, Cultivation, and Extraction of Secondary Metabolites from Marine Sponges-Derived Fungi

These stages have been conducted due to our previous study ${ }^{12}$. Marine sponge $N$. chaliniformis was taken at Mandeh Island, West Sumatra, Indonesia using scuba diving method. Furthermore, isolation of fungi Rasayan J. Chem., 12(3), 1463-1469(2019) http://dx.doi.org/10.31788/RJC.2019.1235284

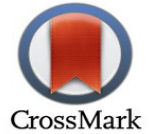


from $N$. chaliniformiswas conducted using Sabouraud Dextrose Agar as a medium and incubated at a temperature of $27-29^{\circ} \mathrm{C}$ for 5-7 days then purified by using the scratch method. We obtained A. nomius from this sponge and cultured in big scale by using rice as a medium for 4 to 8 weeks ${ }^{7}$. After this fungus overgrown on rice, then it was extracted using ethyl acetate (1:1).

\section{Fractionation of Secondary Metabolites}

Isolation compounds of $27.53 \mathrm{~g}$ of crude extract from $A$. nomius were done by vacuum liquid chromatography with n-hexane, ethyl acetate, dichloromethane, and methanol as mobile phase and silica gel $60(0.063-0.2 \mathrm{mesh})$ as the stationary phase. Thin-layer chromatography (TLC) was used for monitoring every vials-collected and combining as one fraction that has the same spot pattern on TLC. In this study, we successfully collected 5 fractions. Furthermore, these fractions were submitted to the HPLC to be characterized by every compound in one fraction.

\section{MTT Assay}

\section{Sample Screening}

Cytotoxic activity of HCT 116 as a colon adenocarcinoma cell line was conducted using MTT assay. These cell lines were obtained from the Laboratory of Biotechnology and Cell Culture Pharmacy Faculty, International Islamic University Malaysia. HCT 116 was cultured in DMEM Gibco ${ }^{\mathrm{TM}}$. This cell was seeded in 96-well plates (density: 6x103 cells/well) and incubated at $37^{\circ} \mathrm{C}, 98 \%$ relative humidity with $5 \% \mathrm{CO}_{2}$. After overnight incubation (confluence), the fraction of Ethyl acetate A. nomius extract was added with concentrations of $100 \mu \mathrm{g} / \mathrm{mL}, 10 \mu \mathrm{g} / \mathrm{mL}, 1 \mu \mathrm{g} / \mathrm{mL}$ and $0.1 \mu \mathrm{g} / \mathrm{mL}$. Then $100 \mu \mathrm{LMTT}$ (5 $\mathrm{mg} / \mathrm{mL}$ ) was added and incubated for 4 hours. The absorbance was measured using Tecan Microplate at $560 \mathrm{~nm}$ using DMSO as blank and Doxorubicin as a positive control. The absorbance of each fraction against HCT 116 colon cancer cells was expressed as viability percentage. ${ }^{13}$

\section{Antibacterial Activity}

Salmonellatyphosa, Pseudomonas aeruginosa, Vibrio cholera, Escherichiacoli as Gram-negative bacteria and Enterococcus faecalis, Staphylococcus aureus, Staphylococcusmutans, Bacillus subtilis, Micrococcusluteus, Staphylococcusepidermidis as Gram-positive bacteria had been prepared for this study. Every fraction was diluted being $5 \%$ with DMSO as a test solution. One piece of sterile disk paper $(6 \mathrm{~mm})$ was soaked in the test solution. DMSO was used for negative control and chloramphenicol disk as a positive control. Zone of inhibition (mm) was measured after incubation at a temperature of $37{ }^{\circ} \mathrm{C}$ for 24 hours. $^{14}$

\section{High-Performance Liquid Chromatography}

Every fraction was diluted with methanol HPLC (1:1), and then pipetted out $50 \mu \mathrm{L}$ to the HPLC vial and added with methanol HPLC until the total volume of $500 \mu \mathrm{L}$. Furthermore, diluted sample on HPLC vial was submitted to UltiMate ${ }^{\mathrm{TM}} 3000$ UHPLC with column $\mathrm{C}_{8}, 4.6 \times 150 \mathrm{~mm}, 5 \mu \mathrm{m}$, mobile phase A: $\mathrm{H}_{2} \mathrm{O}$ with $0.1 \%$ TFA; B: methanol, flow rate: $1 \mathrm{~mL} / \mathrm{min}$. Gradient elution from0 to $35 \mathrm{~min}$ was $10-100 \% \mathrm{~B}$ while 35 to 60 min was $100-10 \% \mathrm{~B}$.

\section{RESULTS AND DISCUSSION}

Aspergillus nomius is a species of fungi as a potential source for cytotoxic and other bioactivity ${ }^{15}$. In our study, we successfully isolated. nomius from marine sponge $N$. chaliniformis. As much as $27.53 \mathrm{~g}$, crude ethyl acetate extract of $A$. nomius was obtained. The result of VLC column was obtained 5 fractions that we collect based on the same spot pattern on TLC. These fractions were characterized based on its retention time of compounds contained in each fraction by using HPLC. In Figure 1, HPLC chromatogram for every fraction is shown. Every peak that appeared in $235 \mathrm{~nm}$ were representative why these fractions were different from each other.

Based on HPLC chromatograms, the same main peak was observed in fraction II to $\mathrm{V}$, with the retention time around $2.67 \mathrm{~min}$. On the other hand, every fraction exhibited different main peak such as a peak in the retention time of 18.34 and 31.74 which were only observed in fraction I. For fraction III and IV there 
RASĀYAN J. Chem.

Vol. 12 | No. 3 |1463 - 1469| July - September | 2019

were also 2 main peaks in retention time around 22.15 and $22.95 \mathrm{~min}$. The peak in retention time around 26.37 min appeared as the main peak in fraction IV and V.

Cytotoxic screening from a natural product is important to be conducted due to the prospecting of potential anticancer agents ${ }^{16}$. In this study, MTT assay was used to evaluate the cytotoxic activity of the fifth fractions. Here, we reported cytotoxic activity of the fifth fractions against HCT 116 colon cancer cell line. Figure 2 showed fraction II was the most potent cytotoxic activity with $\mathrm{IC}_{50}$ of $5.28 \mu \mathrm{g} / \mathrm{mL}$ followed by fraction IV, fraction III, fraction $\mathrm{V}$ then fraction I.Doxorubicin was used as a positive control against HCT 116 colon cancer cell with $\mathrm{IC}_{50}$ of $0.47 \mu \mathrm{g} / \mathrm{mL}$.
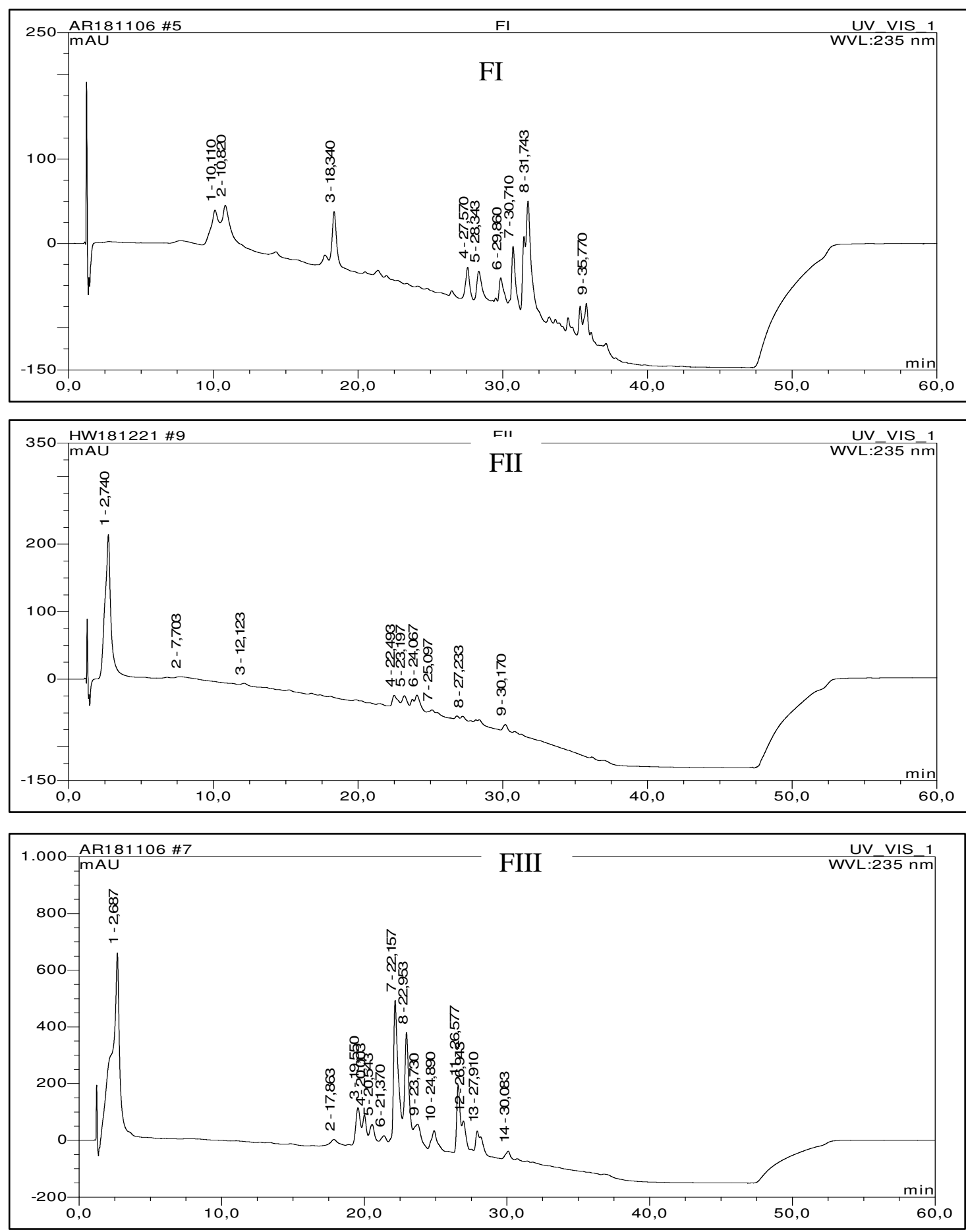

FUNGUS Aspergillus nomius NC06 
RASĀYAN J. Chem.

Vol. 12 | No. 3 |1463 - 1469| July - September | 2019
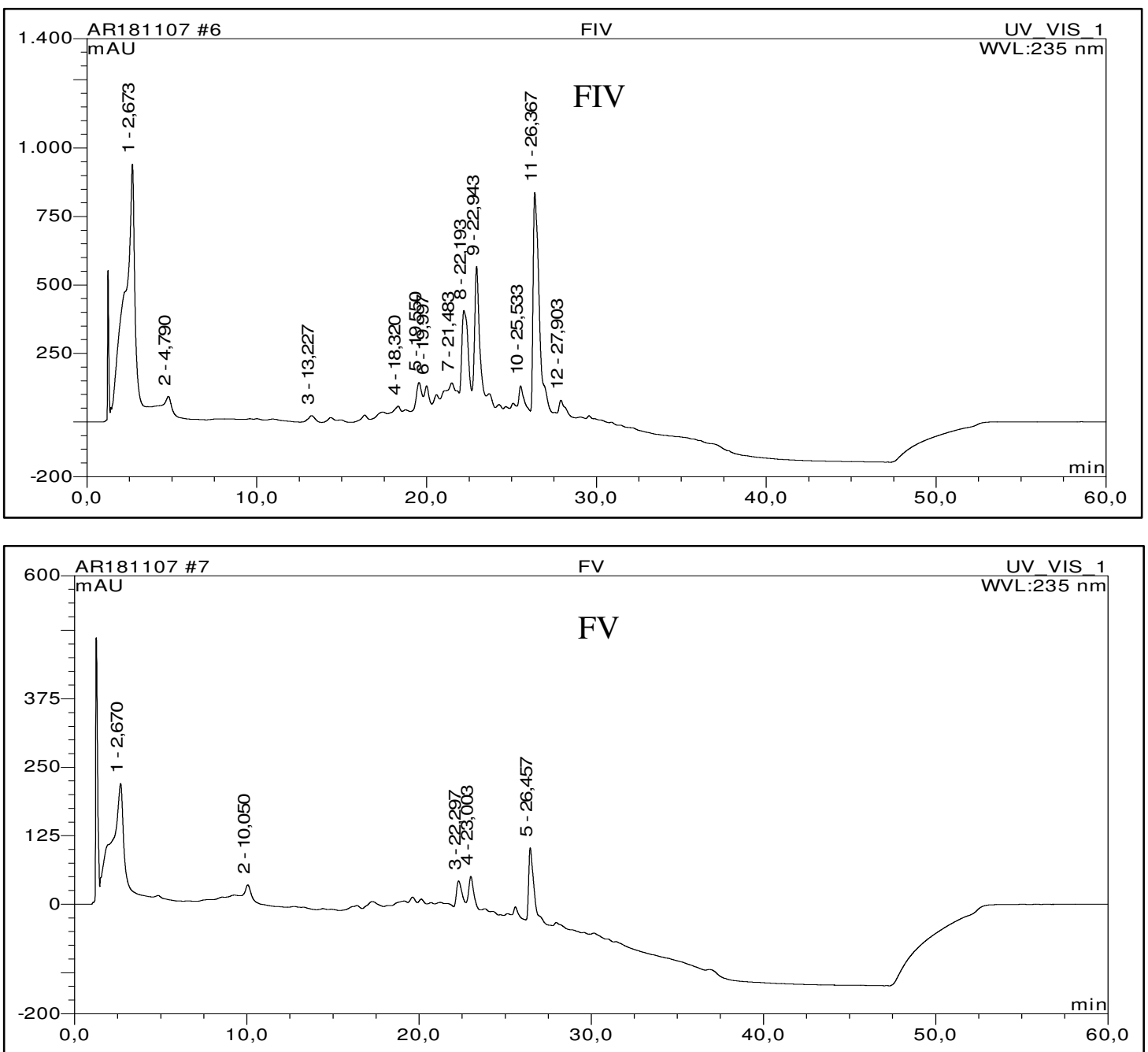

Fig.-1: HPLC Chromatogram of Fraction I to Fraction V; Column $\mathrm{C}_{8}, 4.6$ x $150 \mathrm{~mm}, 5 \mu \mathrm{m}$, Mobile Phase $\mathrm{A}$ : $\mathrm{H}_{2} \mathrm{O}$ with $0.1 \%$ TFA; B: Methanol, Flow Rate: $1 \mathrm{~mL} / \mathrm{min}$.

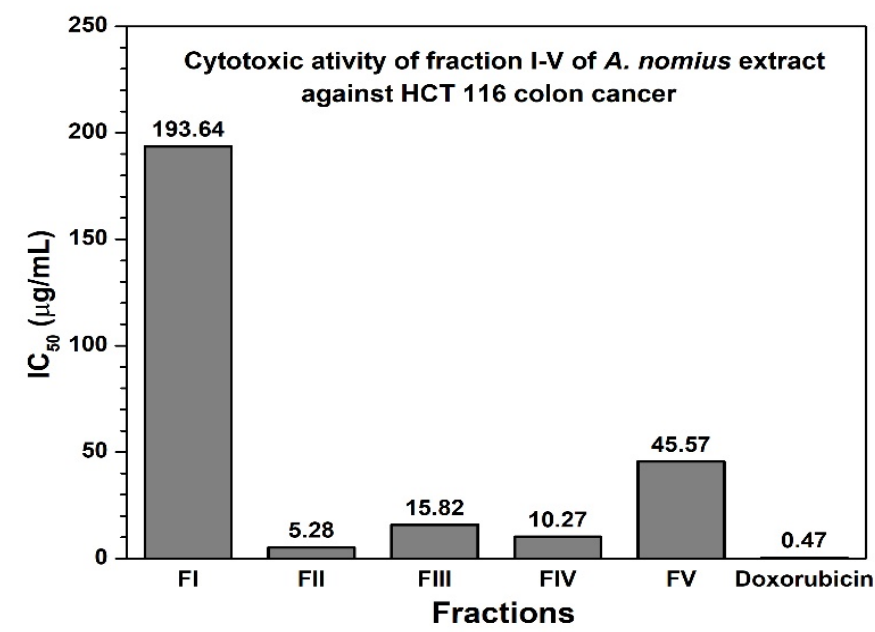

Fig.-2: Cytotoxic Activity of Fraction I-V of A. nomius extract against HCT 116 colon Cancer. 
RASĀYAN J. Chem.

Vol. 12 | No. 3 |1463 - 1469| July - September | 2019

Antibacterial activity test is listed in Table-1. In this study, fraction II and III showed potential antibacterial activity that can inhibit ten pathogenic bacteria with inhibition zone more than $10 \mathrm{~mm}$. In Table-1 also showed Fraction III can inhibit Gram-positive and Gram-negative bacteria with inhibition diameter zone $(\mathrm{mm})$ of $15.43 \pm 0.27,15.38 \pm 0.33,16.7 \pm 0.55,15.41 \pm 0.28,15.98 \pm 0.29,13.95 \pm 0.58$, 14.76 $\pm 0.94,15.86 \pm 1.5,17.53 \pm 0.62,15.71 \pm 0.45$ againstS. typhosa, $P$. aeroginosa, V. cholera, E. faecalis, S. epidermidis, S. aureus, E. coli, S. mutans, B. subtilis, M. luteus, respectively.

Table-1: Antibacterial Activity of Fraction I-V of A. nomius extract

\begin{tabular}{c|c|c|c|c|c}
\hline \multirow{2}{*}{ Pathogenic Bacteria } & \multicolumn{5}{|c}{ Inhibition Zone $(\mathrm{mm}) \pm$ Standard Deviation (SD) } \\
\cline { 2 - 6 } & Fraction I & Fraction II & Fraction III & Fraction IV & Fraction V \\
\hline S. typhosa & $10.83 \pm 1.41$ & $13 \pm 0.7$ & $15.43 \pm 0.27$ & - & $7.28 \pm 0.12$ \\
\hline P. aeroginosa & $8.2 \pm 0.08$ & $12.66 \pm 0.79$ & $15.38 \pm 0.33$ & - & $7.85 \pm 0.56$ \\
\hline V. cholerea & $12.75 \pm 0.55$ & $14.31 \pm 0.20$ & $16.7 \pm 0.55$ & - & - \\
\hline E. faecalis & $9.78 \pm 0.54$ & $14.86 \pm 0.57$ & $15.41 \pm 0.28$ & - & - \\
\hline S. epidermidis & $9.55 \pm 0.35$ & $12.4 \pm 1.01$ & $15.98 \pm 0.29$ & $7.28 \pm 0.18$ & $8.18 \pm 0.11$ \\
\hline S. aerus & $8.33 \pm 0.15$ & $12.16 \pm 0.05$ & $13.95 \pm 0.58$ & - & - \\
\hline E. coli & $10.73 \pm 1.31$ & $13.38 \pm 1.32$ & $14.76 \pm 0.94$ & $7.38 \pm 0.12$ & $8.4 \pm 0.26$ \\
\hline S. mutans & - & $10.6 \pm 0.43$ & $15.86 \pm 1.5$ & - & - \\
\hline B. subtilis & $9.55 \pm 1.3$ & $12.85 \pm 1.58$ & $17.53 \pm 0.6$ & - & $7.4 \pm 0.57$ \\
\hline M. luteus & $10.21 \pm 0.45$ & $14.05 \pm 1.21$ & $15.71 \pm 0.45$ & $6.83 \pm 0.32$ & $7.53 \pm 0.15$ \\
\hline
\end{tabular}

The result of cytotoxic and antibacterial activity showed that fraction II and III were potential fractions to be furtherly studied. Due to of HPLC chromatogram in these fractions, there was some peak that showed as main peak such us retention time of $2.74 \mathrm{~min}, 22.16 \mathrm{~min}, 22.95$ and $26.58 \mathrm{~min}$. Based on library hits of UV spectra of this main peak were probably eudesmic acid (2.74 min), spongiciadin E (22.16 min), and Notoamide E $(26.58 \mathrm{~min})$. Another main peak of these fractions in the retention time of 22.95 min was undetected or no spectra library hits found (Figure 3). Further study is needed to prove what compounds are contained in these fractions using the spectroscopy method. However, these main peaks might be responsible for the potential cytotoxic and antibacterial activity of fraction II and III.
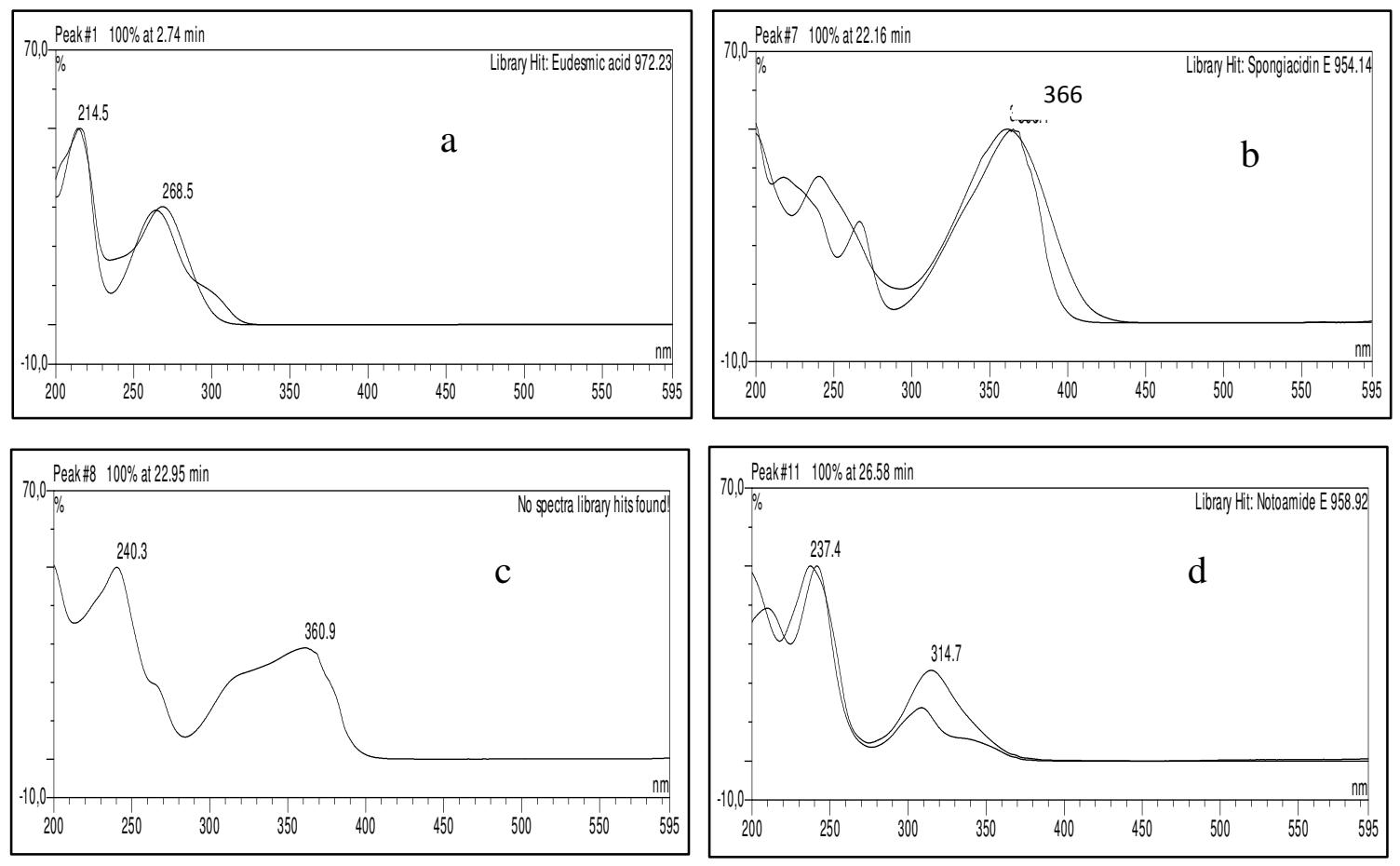

Fig.-3: UV Spectra of Main Peaks from Fraction II and III. (a) Library Hit of UV Spectra of the Compound in Retention Time 2.74 min (eudesmic acid), (b) 22.16 min (spongiacidin E), (c) 22.95 min (no spectra library hit), (d) 26.58 min (notoamide E). 
RASĀYAN J. Chem.

Vol. 12 | No. 3 |1463 - 1469| July - September | 2019

Lack of information on secondary metabolites of A. nomiusas cytotoxic and antibacterial activity. However, the study of Gloeret al., (1989) and Staub et al., (1992) reported bioactive compounds from $A$. nomius, isolated from pine sawfly Diprionsimilis, such us nomine, and aspernomine which are indole diterpenoids. This study reported that aspernomine exhibits cytotoxicity against solid tumor cell such us A-549 lung carcinoma, MCF-7 breast adenocarcinoma, and HT-29 colon adenocarcinoma with IC $_{50}$ values of $3.09,4.93$, and $3.08 \mu \mathrm{g} / \mathrm{mL}$, respectively ${ }^{17,18}$. Compared with $A$. nomius that we isolated from marine sponge $N$. chalinifromis may produce different secondary metabolite due to the different environment ${ }^{19}$.

Antibacterial from Aspergillus genus repeatedly showed strong activity. Study of Li et al., (2012) successfully reported aspergiterpenoid A, sydonol, and sydonic acid from Aspergillus sp. had potential antibacterial activity towards $S$. albus, B. subtilis, B. cereus, S. lutea, E. coli, and M. tetragenus with MIC range values of 1.25 to $5 \mu \mathrm{M}^{20}$. Moreover, a new cyclic hexapeptide and a new isocoumarin isolated from sponge-associated fungus $A$. similanensis showed potential antibacterial activity against $S$. aureus, $B$. subtilis, E. coli, and P. aeruginosa with MIC value of below $2.56 \mu \mathrm{g} / \mathrm{mL}^{21}$.

\section{CONCLUSION}

Aspergillus nomiuswhich was isolated from marine sponge $N$. chaliniformis showed potential cytotoxic and antibacterial activities. Fraction II and III were found most cytotoxic against HCT 116 colon cancer $\left(\mathrm{IC}_{50}<20 \mu \mathrm{g} / \mathrm{mL}\right.$ ) and antibacterial activity (inhibition zone $>12 \mathrm{~mm}$ ) against $S$. typhosa, P. aeroginosa, $V$. cholera, E. faecalis, S. epidermidis, S. aureus, E. coli, S. mutans, B. subtilis, M. luteus. Further study is recommended to identify the active compound that is responsible for cytotoxic against HCT 116 colon cancer and ten pathogenic bacteria.

\section{ACKNOWLEDGMENT}

Authors thank Prof. Dr. Peter Proksch and Mrs. Ni P. Ariantari (Institute of Pharmaceutical Biology and Biotechnology, Heinrich Heine University Düsseldorf, Germany) for HPLC analysis of fractions. This research was funded by The Ministry of Research and Technology, Indonesia through PMDSU Research, 059/SP2H/LT/DRPM/IV/2018.

\section{REFERENCES}

1. U. Hentschel, K. M. Usher, and M. W. Taylor, FEMS Microbiology Ecology, 55(2),167(2006), DOI: $10.1111 / \mathrm{j} .1574-6941.2005 .00046 . \mathrm{x}$

2. G. Wang, Journal of Industrial Microbiology and Biotechnology, 33, 545(2006),DOI: 10.1007/s10295-006-0123-2

3. J. Wiese, B. Ohlendorf, M. Blumel, R. Schmaljohann and J. F. Imhoff, Mar. Drugs, 9(4), 561(2011), DOI: 10.3390/md9040561

4. P. Bhadury, B. T. Mohammad, and P. C. Wright, J. Ind. Microbiol. Biotechnol, 33, 325(2006), DOI: $10.1007 / \mathrm{s} 10295-005-0070-3$

5. V. Vasanthabharathi, and S. Jayalakshmi, African Journal of Biotechnology, 10(54), 11224(2011), DOI: $10.5897 / A J B 11.296$

6. V. Thiel, S. Leininger, R. Schmaljohann, F. Brummer, and F. Johannes, Microbial Ecology, 54(1), 101(2007), DOI: 10.1007/s00248-006-9177-y

7. J. Kjer, D. Abdessamad, H. A. Amal, P. Peter, Nature Protocols, 5, 479(2010), DOI: 10.1038/nprot.2009.233

8. P. Proksch, and R. E. Edrada, Appl. Microbiol. Biot., 59(2),125(2002), DOI: 10.1007/s00253-0021006-8

9. Y. M. Lee, H. Li, J. Hong, H. Y.Cho, K. S. Bae, M. A. Kim, D. K. Kim, and J. H. Jung, Archives of Pharmacal Research, 33(2), 231(2010), DOI: 10.1007/s12272-010-0207-4

10. Q. Wu, H. L.Long, D. Liu, P. Proksch, and W. H. Lin, Journal of Asian Natural Products Research,17(12), 1137(2015), DOI:10.1080/10286020.2015.1119127

11. M. A. Artasasta, Yanwirasti, A. Djamaan, D. Handayani, Journal Applied of Pharmaceutical Science,7(12), 174(2017), DOI:10.7324/JAPS.2017.71225 
RASĀYAN J. Chem.

Vol. 12 | No. 3 |1463 - 1469| July - September | 2019

12. D. Handayani, M. A. Artasasta, J. App. Pharmaceutical Science, 7(05), 066(2017), DOI: 10.7324/JAPS.2017.70512

13. B. Yamini and R. Nanthini, RASAYAN Journal Chemistry, 11(2), 440(2018), DOI: 10.31788/RJC.2018.1121992

14. D. U. C. Rahayu, Hartono, and P. Sugita, RASAYAN Journal Chemistry, 11(2),762(2018), DOI: 10.31788/RJC.2018.1122076

15. G. M. Staub, J. B. Gloer, D. T. Wicklow and P.F. Dowd, Tetrahedron Letters, 34(16), 2569(1993), DOI: $10.1016 / \mathrm{S} 0040-4039(00) 77627-1$

16. N. G. M. Gomes, F. Lefranc, A. Kijjoa and R. Kiss, Marine Drugs, 13(6), 3950(2015), DOI: $10.3390 / \mathrm{md} 13063950$

17. J. B. Gloer, B. L. Rinderknecht, D. T. Wicklow and P. F. Dowd, J. Org. Chem, 54(11), 2530(1989), DOI: $10.1021 /$ jo00272a012

18. G. M. Staub, K. B. Gloer and J. B. Gloer, J. Am. Chem. Soc., 114(3), 1015(1992), DOI: 10.1021/ja00029a033

19. S. Romano, S. A. Jackson, S. Patry and A. D. W. Dobson, Marine Drugs,16(7), 224(2018), DOI: 10.3390/md16070244

20. D. Li, Y. Xu, C. L. Shao, R. Y. Yang, C. J. Zheng, Y. Y. Chen, X. M. Fu, P. Y. Qian, Z. G. She, N. J. Voogd and C. Y. Wang, Marine Drugs, 10(1), 234(2012), DOI: 10.3390/md10010234

21. C. Prompanya, C. Fernandes, S. Cravo, M. M. M. Pinto, T. Dethoup, A. M. S. Silva and A. Kijjoa, Marine Drugs,13(3), 1432(2015), DOI: 10.3390/md13031432

[RJC-5284/2019] 